University of Wollongong

Research Online

Faculty of Informatics - Papers (Archive)

Faculty of Engineering and Information

Sciences

$1-1-2007$

\title{
Automated Software Testing and Analysis: Techniques, Practices and Tools
}

Z. Q. Zhou

University of Wollongong, zhiquan@uow.edu.au

B. Scholz

University of Sydney

G. Denaro

Universita di Milano-Bicocca, Italy

Follow this and additional works at: https://ro.uow.edu.au/infopapers

Part of the Physical Sciences and Mathematics Commons

\section{Recommended Citation}

Zhou, Z. Q.; Scholz, B.; and Denaro, G.: Automated Software Testing and Analysis: Techniques, Practices and Tools 2007.

https://ro.uow.edu.au/infopapers/476

Research Online is the open access institutional repository for the University of Wollongong. For further information contact the UOW Library: research-pubs@uow.edu.au 


\title{
Automated Software Testing and Analysis: Techniques, Practices and Tools
}

\author{
Abstract \\ As computer systems are permeating our society in daily life and are performing an increasing number of \\ critical tasks, research in software testing and analysis has become of paramount importance. Although \\ we are currently not able to prove program correctness for real-world applications, rigorous software \\ development processes in combination with testing provides us with confidence in the quality of \\ software. Software testing and analysis, however, is a very involved task. As the size and complexity of \\ software continue to grow, manual testing becomes very tedious. Automation of software testing and tool \\ support for testing, therefore, have been emerging as a key technology to quality assurance of today is \\ software industry. As research in software testing and analysis has become increasingly active, there is \\ also a growing trend towards combining formal methods and informal techniques for program \\ verification. \\ Disciplines \\ Physical Sciences and Mathematics \\ Publication Details \\ This paper was originally published as: Zhou, ZQ, Scholz, B \& Denaro, G, Automated Software Testing and \\ Analysis: Techniques, Practices and Tools, 40th Annual Hawaii International Conference on System \\ Sciences (HICSS 2007), Waikoloa, Hawaii, USA, January 2007, 260. Copyright IEEE 2007
}




\section{Automated Software Testing and Analysis: Techniques, Practices and Tools}

\author{
Zhi Quan Zhou \\ School of IT \& Computer Science \\ University of Wollongong \\ Wollongong \\ NSW 2522 \\ Australia \\ Email: zhiquan@uow.edu.au
}

\author{
Bernhard Scholz \\ School of Information Technologies \\ The University of Sydney \\ Sydney \\ NSW 2006 \\ Australia \\ Email: scholz@it.usyd.edu.au
}

\author{
Giovanni Denaro
}

\author{
Dipartimento di Informatica \\ Sistemistica e Comunicazione \\ Università di Milano-Bicocca \\ Via Bicocca degli Arcimboldi 8 \\ Milano, MI 20126, Italy \\ Email:denaro@disco.unimib.it
}

As computer systems are permeating our society in daily life and are performing an increasing number of critical tasks, research in software testing and analysis has become of paramount importance. Although we are currently not able to prove program correctness for real-world applications, rigorous software development processes in combination with testing provides us with confidence in the quality of software. Software testing and analysis, however, is a very involved task. As the size and complexity of software continue to grow, manual testing becomes very tedious. Automation of software testing and tool support for testing, therefore, have been emerging as a key technology to quality assurance of today's software industry. As research in software testing and analysis has become increasingly active, there is also a growing trend towards combining formal methods and informal techniques for program verification.

The HICSS Minitrack Automated Software Testing and Analysis: Techniques, Practices and Tools is within the Software Technology Track. The aim of this Minitrack is to bring together researchers and practitioners to present their research results and exchange ideas and experience in software testing and analysis, especially in their automation and/or tool support, and in the combination of formal methods and informal techniques.

This Minitrack received eight submissions, one of which was withdrawn later. The Program Committee has selected five papers. Each submission was reviewed by at least three referees, and papers were selected in the later stage of a two-week discussion phase. We would like to thank the members of the Program Committee for their hard work.

The accepted papers were from the following institutions and companies around the world: ETH Zurich (Switzerland), AXA Rosenberg (USA), Indian
Institute of Technology Kanpur (India), HewlettPackard Laboratories (USA), Swinburne University of Technology (Australia), The University of Hong Kong (Hong Kong), East China Normal University (China), University of Perpignan (France), CNRS (France), and The University of Manchester (UK).

\section{Minitrack Program Committee}

Johann Blieberger, Vienna University of Technology, Austria

Bernd Burgstaller, University of Sydney, Australia Bill Bush, Sun Microsystems, USA

Licia Capra, University College London, UK

T.Y. Chen, Swinburne University of Technology, Australia

S.C. Cheung, Hong Kong University of Science and Technology, Hong Kong

Rance Cleaveland, University of Maryland, USA

Wolfgang Grieskamp, Microsoft Research, USA

Daniel Hoffman, University of Victoria, Canada

Sarfraz Khurshid, The University of Texas at Austin, USA

Michael R. Lyu, Chinese University of Hong Kong, Hong Kong

Leonardo Mariani, University of Milano - Bicocca, Italy

Alessandro Orso, Georgia Institute of Technology, USA

Mauro Pezzè, University of Milano - Bicocca, Italy Vugranam Sreedhar, IBM T.J. Watson Research Center, USA

Willem Visser, NASA Ames Research Center, USA

Tao Xie, North Carolina State University, USA 